\title{
Characterization of the $\mathrm{P}_{1}$-purinoceptors mediating contraction of the rat colon muscularis mucosae
}

\author{
S.J. Bailey, ${ }^{1}$ D. Hickman \& ${ }^{2}$ S.M.O. Hourani \\ Receptors and Cellular Regulation Research Group, School of Biological Sciences, University of Surrey, Guildford, \\ Surrey GU2 5XH
}

1 Previous studies had shown that adenosine and adenine nucleotides including adenosine $5^{\prime}$ triphosphate (ATP) caused contraction of the rat colon muscularis mucosae via $P_{1}$ and $P_{2 Y}$-purinoceptors respectively, and that the stable ATP analogue adenylyl $5^{\prime}-(\beta, \gamma$-methylene)diphosphonate (AMPPCP) had an unexpected direct action on the $P_{1}$-purinoceptors. The $P_{1}$-purinoceptors have now therefore been further characterized by use of the adenosine analogues $5^{\prime}-\mathrm{N}$-ethylcarboxamidoadenosine (NECA) and $\mathrm{N}^{6}$-cyclopropyladenosine (CPA) and the antagonist 1,3-dipropyl-8-cyclopentylxanthine (DPCPX), which is selective for the $A_{1}$ subtype. The $P_{2}$-purinoceptor antagonist suramin was also used, to investigate the selectivity of the $P_{2}$ agonists.

2 The order of potency of $P_{1}$ agonists for contraction was CPA $>$ NECA $>$ AMPPCP $\geq$ adenosine, and DPCPX (1 nM) caused greater than two fold shifts to the right of the log concentration-response curves for each of these agonists, although the shifts were not always parallel and Schild analysis of the inhibition of the effect of adenosine resulted in a plot with a slope greater than unity. These results indicate that the $P_{1}$-purinoceptor mediating contraction is of the $A_{1}$ subtype, as has been found in other tissues in which adenosine causes contraction.

3 The $P_{2}$-purinoceptor antagonist suramin $(300 \mu \mathrm{M})$ had no effect on the responses to adenosine or to AMPPCP, but abolished contractions induced by the related stable ATP analogue adenosine $5^{\prime}-(\alpha, \beta-$ methylene)triphosphonate (AMPCPP). Contractions induced by ATP, which were not affected by DPCPX (10 nM) alone, were only partially inhibited by suramin $(300 \mu \mathrm{M})$, revealing an $A_{1}$ component to its action which could be blocked by DPCPX (10 nM).

4 In conclusion, these results show that the rat colon muscularis mucosae possesses contractile $A_{1}$ receptors in addition to the previously characterized $P_{2 Y}$ receptors, and confirms our finding that the stable ATP analogue, AMPPCP, has an unexpected direct action on these $A_{1}$ receptors.

Keywords: Purinoceptors; adenosine; ATP; suramin; rat colon muscularis mucosae

\section{Introduction}

The pharmacological effects of extracellular adenosine and adenine nucleotides are mediated by specific receptors known as purinoceptors, of which two main classes are recognised, $P_{1}$-purinoceptors which respond to adenosine and $\mathbf{P}_{2}$-purinoceptors which respond to adenosine 5'-triphosphate (ATP) and adenosine 5'-diphosphate (ADP) (Burnstock, 1978). The methylxanthines such as theophylline and its analogues are competitive antagonists at $\mathbf{P}_{1}$-purinoceptors and inhibit the effects of adenosine but not of ATP (Burnstock, 1978), while until recently no reversible competitive antagonists existed for the $P_{2}$-purinoceptor (Fedan \& Lamport, 1990). However the trypanocidal drug, suramin, has now been demonstrated to be a competitive antagonist of the actions of ATP on a number of smooth muscle preparations, although it appears to equilibrate with the receptors very slowly (Dunn \& Blakely, 1988; Den Hertog et al., 1989a,b; Hoyle et al., 1990; Leff et al., 1990; Von Kugelgen et al., 1990). A complicating factor in the study of purinoceptor pharmacology is that as well as acting on $P_{2}$-purinoceptors, ATP (and some of its analogues) is rapidly and sequentially dephosphorylated by ectonucleotidases present on the surface of cells, ultimately to adenosine which has its own effects on $P_{1}$-purinoceptors and is also removed by uptake into cells and by deamination to the inactive inosine (Pearson \& Slakey, 1990).

$P_{1}$-purinoceptors have been subdivided into $A_{1}$ and $A_{2}$, on the basis of different structure-activity relationships for agonists and antagonists and, in general, different second messenger coupling systems, with $A_{1}$ receptors causing inhibition of adenylate cyclase and $A_{2}$ receptors causing stimulation,

${ }^{1}$ Present address: University Department of Pharmacology, Mansfield Road, Oxford OX1 3TH.

${ }^{2}$ Author for correspondence. although this is not a criterion for receptor subdivision and other coupling systems probably exist. On $A_{1}$ receptors $N^{6}$ substituted adenosine analogues such as $\mathrm{N}^{6}$ cyclopentyladenosine (CPA) are more potent than $5^{\prime}$-substituted analogues such as $5^{\prime}$-N-ethylcarboxamidoadenosine (NECA), whereas on $A_{2}$ receptors the potency order is reversed. Radioligand binding studies with $A_{1}$ and $A_{2}$ selective ligands have confirmed the existence of these two subtypes, and selective antagonists have been developed (for reviews see Bruns, 1990a,b; Jacobson, 1990; Daly, 1990). However, characterization of adenosine receptor subtypes in isolated smooth muscle preparations has not always been clear-cut, as agonist potency orders have not always fallen into one of the two patterns expected, and indeed this has led to the suggestion of a third major subclass, $A_{3}$ (Ribeiro \& Sebastiao, 1986), although this has not gained wide acceptance. Another problem has been that some of the antagonists which have been reported to be $A_{1}$-selective in other tissues fail to show selectivity in functional studies in smooth muscle, although recently 1,3-dipropyl-8-cyclopentylxanthine (DPCPX) has been shown to act as a selective, competitive $A_{1}$ antagonist in guinea-pig and rat tissues (Collis et al., 1987; 1989; Collis, 1990).

$P_{2}$-purinoceptors on smooth muscle have also been subdivided, the major division being into $P_{2 X}$ and $P_{2 Y}$, mediating contraction or relaxation of smooth muscle respectively (Burnstock \& Kennedy, 1985; Gordon, 1986; Burnstock, 1990). This receptor classification is largely based on different structure-activity relationships for ATP analogues (Cusack \& Hourani, 1990), as well as on the different responses elicited. On $\mathbf{P}_{2 x}$-purinoceptors stable analogues of ATP, such as adenylyl $5^{\prime}-(\beta, \gamma-$ methylene)diphosphonate (AMPPCP) and adenosine $5^{\prime}-(\alpha, \beta$-methylene)triphosphonate (AMPCPP) are more potent than ATP which is equipotent with its 2substituted analogues such as 2-methylthioadenosine 5 - 

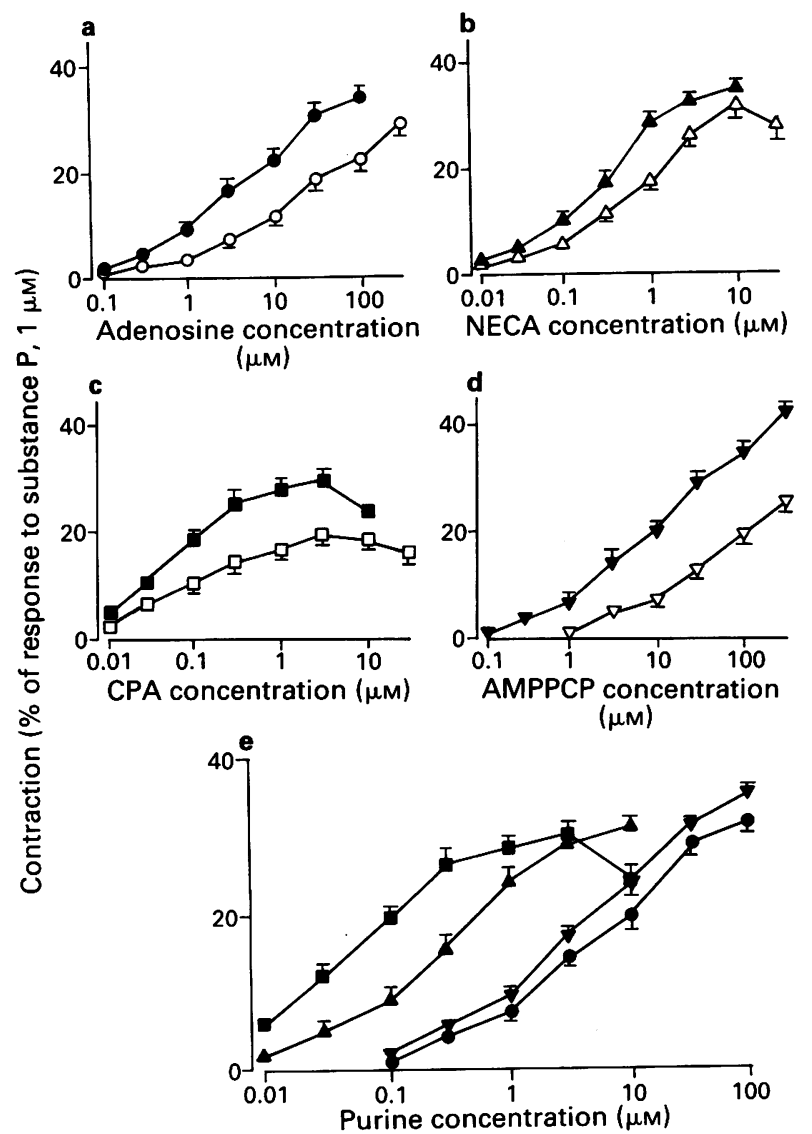

Figure 1 Contractions of the rat colon muscularis mucosae to (a) adenosine $(\mathbf{O}, \mathrm{O})$, (b) 5'-N-ethylcarboxamidoadenosine (NECA, $\Delta$, $\Delta$ ), (c) $\mathbf{N}^{6}$-cyclopropyladenosine (CPA, $\square, \square$ ) or (d) adenylyl $5^{\prime}-(\beta$, $\gamma$-methylene)diphosphonate (AMPPCP $\nabla, \nabla)$ alone (closed symbols) or in the presence of 1,3-dipropyl-8-cyclopentylxanthine (DPCPX, $1 \mathrm{~nm}$ ) (open symbols). Each point is the mean of at least 4 determinations, and the vertical bars show the s.e.mean. Control curves for each agonist alone are also shown in (e), for comparison. Each point here is the mean of at least $\mathbf{1 2}$ determinations, and the vertical bars show s.e.mean.

triphosphate (2-MeSATP), whereas on $\mathbf{P}_{2 \mathrm{Y}}$-purinoceptors 2-MeSATP is more potent than ATP which is more potent than AMPPCP and AMPCPP (Burnstock \& Kennedy, 1985). These structure-activity relationships may be complicated in some tissues by the rapid breakdown by ectonucleotidases of ATP and its 2-substituted analogues to adenosine or its 2substituted analogues, which may affect the observed potency of these nucleotides (Welford et al., 1986; 1987). The $\mathbf{P}_{2}$-purinoceptor antagonist, suramin, does not distinguish between the two proposed subtypes, but has a $\mathrm{pA}_{2}$ value of about 5 on both $\mathrm{P}_{2 \mathrm{X}^{-}}$and $\mathrm{P}_{2 \mathrm{Y}}$-purinoceptors (Dunn \& Blakely, 1988; Den Hertog et al., 1989a,b; Hoyle et al., 1990; Leff et al., 1990; Von Kugelgen et al., 1990).

We have recently shown that in the rat colon muscularis mucosae preparation both $\mathbf{P}_{1}$ - and $\mathbf{P}_{\mathbf{2}}$-purinoceptors exist and mediate contraction, and that the $\mathrm{P}_{2}$-purinoceptor present is, unexpectedly, of the $P_{2 Y}$ subtype. Furthermore, in this preparation AMPPCP, but not ATP, MeSATP or AMPCPP, acts via the $P_{1}$ rather than the $P_{2}$-purinoceptors, as it is inhibited by the selective $P_{1}$-purinoceptor antagonist, 8sulphophenyltheophylline (8-SPT), and this $P_{1}$ effect is direct as the breakdown of AMPPCP in this tissue is far slower than that of ATP which itself is unaffected by 8-SPT (Bailey \& Hourani, 1990). Because of these unexpected findings, we decided to investigate further the purinoceptors in this tissue by using the adenosine analogues NECA and CPA, as well as the $A_{1}$-selective antagonist DPCPX, to determine whether $A_{1}$ or $A_{2}$ receptors were present, and by using the $P_{2}$ antagonist
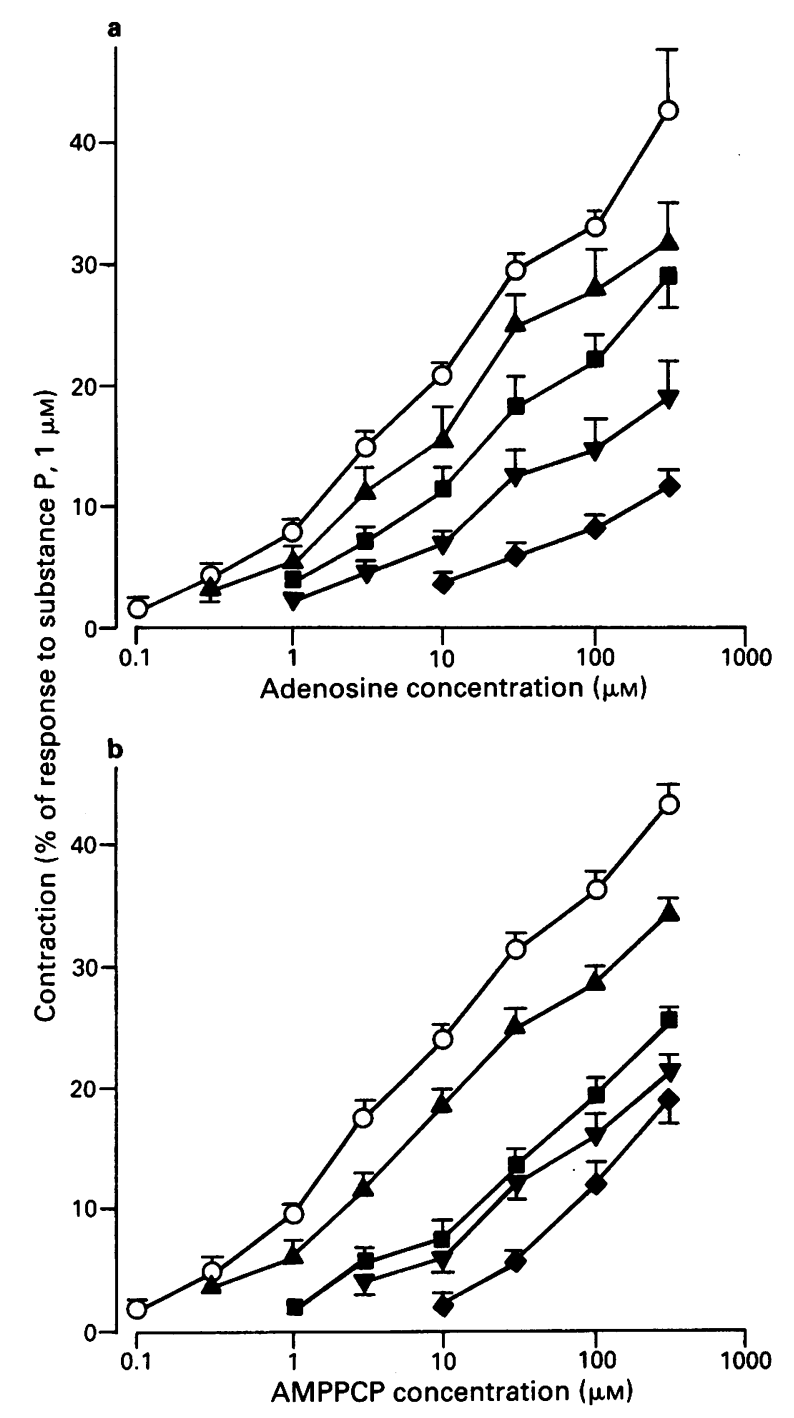

Figure 2 Contractions of the rat colon muscularis mucosae to (a) adenosine or (b) AMPPCP alone $(O)$ or in the presence of $0.3 \mathrm{nM}(\Delta)$, $1 \mathrm{nM}(\square), 3 \mathrm{nM}(\nabla)$ or $10 \mathrm{nM}(\diamond)$ DPCPX. Each point is the mean of at least 6 determinations, and the vertical bars show s.e.mean. For abbreviations, see legend to Figure 1.

suramin to confirm that AMPPCP was acting on $P_{1}$ - and not $\mathbf{P}_{2}$-purinoceptors in this tissue.

\section{Methods}

\section{Pharmacological studies}

Male Wistar rats $(150-200 \mathrm{~g})$ were killed by cervical dislocation and the distal colon removed and placed in warm $\left(32^{\circ} \mathrm{C}\right)$ Tyrode buffer (ionic composition (mM): $\mathrm{Na}^{+} 149.1, \mathrm{~K}^{+}$ $2.8, \mathrm{Ca}^{2+} 1.8, \mathrm{Mg}^{2+} 2.1, \mathrm{Cl}^{-} 147.5, \mathrm{H}_{2} \mathrm{PO}_{4}^{-} 0.3, \mathrm{HCO}_{3}^{-} 11.9$ and glucose 5.6) pregassed with $95 \% \mathrm{O}_{2}: 5 \% \mathrm{CO}_{2}$. The dissection of the rat colon muscularis mucosae was carried out as described by Bailey \& Jordan (1984), with minor modifications. Briefly, a glass pipette, external diameter $5 \mathrm{~mm}$, was placed inside the colon and the outer layer of longitudinal muscle was removed by gentle rubbing with wet cotton wool, leaving a thick walled tube, the muscularis mucosae. This was suspended in a $3 \mathrm{ml}$ organ bath at $32^{\circ} \mathrm{C}$ in gassed Tyrode solution (containing atropine $1 \mu \mathrm{M}$ ), and contractions were recorded isometrically under a resting tension of $1 \mathrm{~g}$ with a Grass FT03 strain gauge and displayed on a Grass 79C polygraph and expressed as a percentage of the contraction induced by substance $\mathrm{P}(1 \mu \mathrm{M})$. The tissue was allowed to equilibrate for $3 \mathrm{~h}$ before control concentration-response 


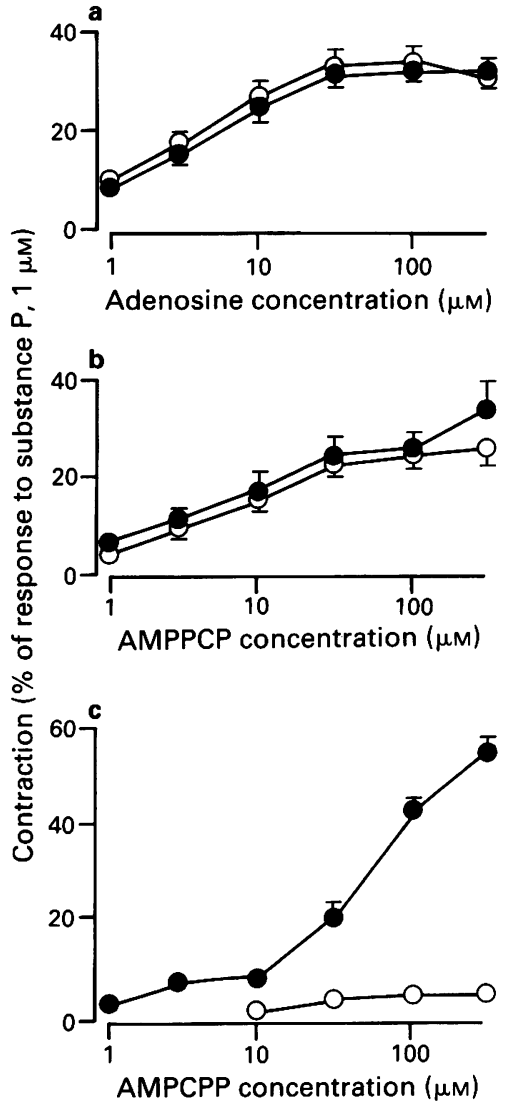

Figure 3 Contractions of the rat colon muscularis mucosae induced by (a) adenosine, (b) AMPPCP or (c) AMPCPP alone (O) or in the presence of suramin $(300 \mu \mathrm{M})(\mathrm{O})$. Each point is the mean of at least 4 determinations, and the vertical bars show the s.e.mean. For abbreviations, see legend to Figure 1.

curves to purinoceptor agonists were determined, followed by incubation with an antagonist for $40 \mathrm{~min}$ before the concentration-responses curves were repeated in the presence of the antagonist. Recovery of responses to the agonists was established following washout of the antagonist for up to $40 \mathrm{~min} ; 12-20 \mathrm{~min}$ were allowed between doses of agonist and the purinoceptor agonists were left in contact with the tissue for $45-90$ s.

\section{Materials}

ATP, AMPPCP, AMPCPP, adenosine and SP were obtained from Sigma UK Ltd, DPCPX, CPA and NECA from Research Biochemicals, and suramin from Bayer, UK. CPA (10 mM) was dissolved in $20 \%$ aqueous ethanol and DPCPX (1 $\mathrm{mM})$ was dissolved in $2 \%$ aqueous dimethylsulphoxide (DMSO) containing $6 \mathrm{~mm} \mathrm{NaOH}$. After dilution corresponding to the final bath concentration of the substances used, these solvents had no effect on the responses of the tissues.

\section{Results}

CPA, NECA, adenosine and AMPPCP each contracted the rat colon muscularis mucosae, and the order of potency was CPA > NECA > AMPPCP $\geq$ adenosine, although maximal responses to adenosine and to AMPPCP could not be achieved due to their rather low potency. Responses to each of these agonists were inhibited by DPCPX (1 nM), although the maximal contractions were depressed by the antagonist (Figure 1). Increasing concentrations of DPCPX (0.3-10 nM) caused increasing inhibition of the responses to adenosine but also depressed the slope of the log concentration-response curve (Figure 2a), and because of the non-parallel nature of

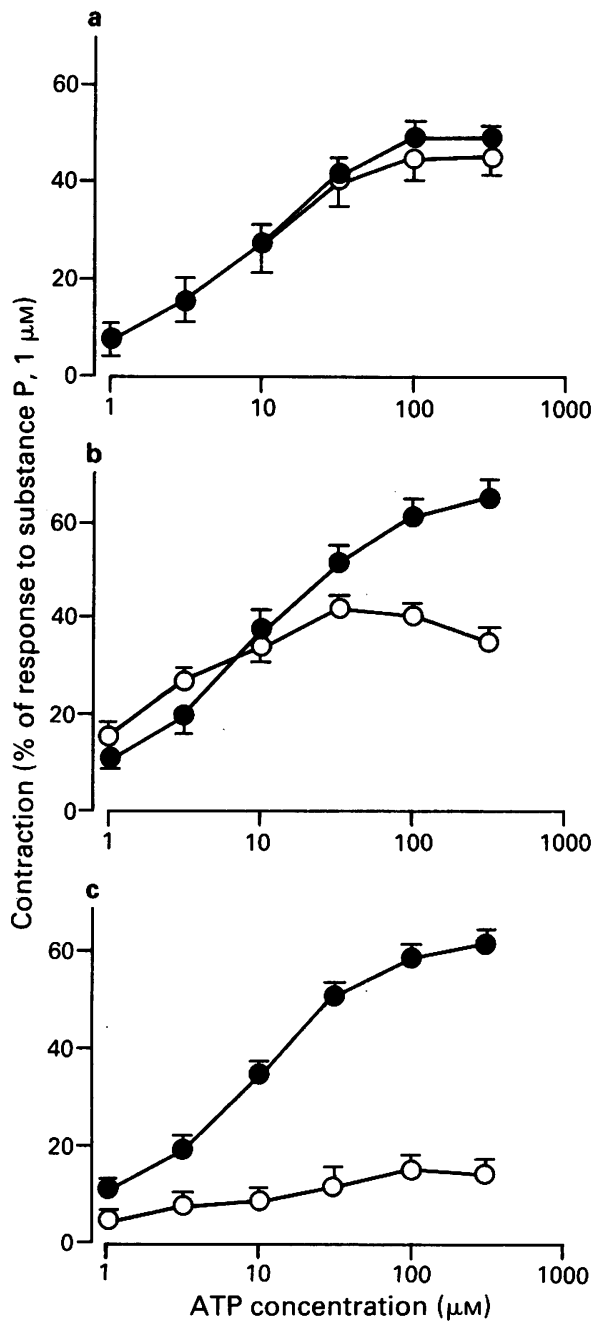

Figure 4 Contractions of the rat colon muscularis mucosae induced by adenosine $5^{\prime}$-triphosphate alone $(0)$ or in the presence of the following antagonists (O): (a) DPCPX (10 nM); (b) suramin $(300 \mu \mathrm{M})$; (c) DPCPX $(10 \mathrm{nM})$ plus suramin $(300 \mu \mathrm{M})$. Each point is the mean of at least 4 determinations, and the vertical bars show the s.e.mean. For abbreviations, see legend to Figure 1.

the shifts Schild analysis was unsatisfactory and resulted in a plot with a slope greater than unity (results not shown). DPCPX (0.3-10 nM) caused similar shifts in the log concentration-response curve to AMPPCP, but did not depress the slope of the curves to the same extent (Figure $2 b$ ). Contractions to adenosine and to AMPPCP were unaffected by suramin $(300 \mu \mathrm{M})$, whereas those to AMPCPP were almost abolished (Figure 3). Contractions to ATP were unaffected by DPCPX $(10 \mathrm{nM})$, partially inhibited by suramin $(300 \mu \mathrm{M})$ and almost abolished by a combination of DPCPX (10 nM) and suramin $(300 \mu \mathrm{M})$ (Figure 4). Whereas the contraction to ATP

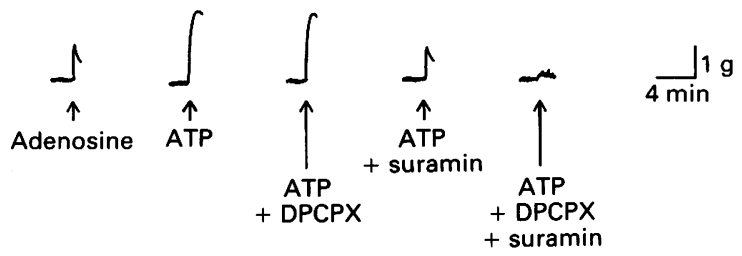

Figure 5 Representative traces showing contractions induced by adenosine $(100 \mu \mathrm{M})$ or by ATP $(100 \mu \mathrm{M})$ alone or in the presence of DPCPX (10 nM), suramin $(300 \mu \mathrm{M})$ or DPCPX $(10 \mathrm{nM})$ plus suramin $(300 \mu \mathrm{M})$. The arrows indicate the point of addition of adenosine or ATP. For abbreviations, see legend to Figure 1. 
alone or in the presence of DPCPX (10 nM) was rather slow and sustained, in the presence of suramin $(300 \mu \mathrm{M})$ this was converted into a faster, quickly reversible contraction similar to that seen with adenosine (see Figure 5 for representative traces).

\section{Discussion}

These results show that in the rat colon muscularis mucosae there is a potency order for adenosine agonists of CPA > NECA and that an $A_{1}$-selective concentration of DPCPX (1 nM) inhibits the effects of adenosine agonists, suggesting that the $P_{1}$-purinoceptor mediating contraction of this tissue is of the $A_{1}$ subtype (Bruns, 1990b; Collis, 1990; Daly, 1990). Adenosine itself was rather less potent than NECA, although its potency may have been reduced by uptake or deamination, and was roughly equipotent with the stable ATP analogue, AMPPCP. In general the postsynaptic inhibitory effects of adenosine in smooth muscle are mediated by $A_{2}$ receptors while the presynaptic inhibition of transmitter release is mediated by $A_{1}$ receptors, although these presynaptic receptors have also been proposed to be of the putative $A_{3}$ subclass (Ribeiro \& Sebastiao, 1986; White, 1988; Kennedy, 1990; Olsson \& Pearson, 1990; Stone, 1991). In those few tissues in which adenosine has been shown to cause contraction, such as the renal vasculature (Kenakin \& Pike, 1987) and the guinea-pig myometrium (Smith et al., 1988), this also appears to be via $A_{1}$ receptors, although the contractions induced by adenosine in the rat anococcygeus have been reported to be insensitive to methylxanthines and may therefore not be mediated by $P_{1}$-purinoceptors (Stone, 1983). It has also been reported that the guinea-pig aorta and trachea each possess both $A_{1}$ and $A_{2}$ receptors which mediate contraction and relaxation respectively, although for adenosine the $\mathrm{A}_{2}$-mediated relaxation is dominant (Farmer et al., 1988; Stoggall \& Shaw, 1990). The existence in the rat colon muscularis mucosae of contractile $P_{1}$-purinoceptors of the $A_{1}$ subtype is therefore consistent with this general pattern.

Although the dissociation constant for DPCPX in the rat colon muscularis mucosae is clearly in the nanomolar range as $1 \mathrm{nM}$ caused greater than a two fold shift in the log concentration-response curves for all the adenosine agonists, an accurate dissociation constant could not be obtained because the shift was not always parallel and Schild analysis resulted in lines with slopes greater than unity. Although this could indicate that DPCPX was not acting in a purely competitive manner in this tissue, we have observed the same problem with 8-SPT in this tissue (unpublished observations) and in the rat duodenum although not in the guinea-pig taenia caeci (Hourani et al., 1991), while Schild plots have been successfully obtained to both antagonists in rat atria and in guinea-pig aorta, atria and trachea (Collis et al., 1989; Collis, 1990). The reason for the differences in Schild slope between the different tissues is not known, but Leung et al. (1990) have suggested a model whereby competitive antagonists may appear to be noncompetitive. This model is based on their finding that unoccupied $A_{1}$ adenosine receptors appear to be tightly bound to G-proteins, and suggests that antagonists bind preferentially to the free receptors whereas agonists bind preferentially to the receptors coupled to the G-proteins, resulting in apparently noncompetitive binding kinetics (Leung et al., 1990). Another possible explanation for the Schild plot having a slope greater than unity is that DPCPX was not at equilibrium with the receptors, but this is unlikely because preliminary experiments with $1 \mathrm{nM}$ DPCPX using a longer incubation time ( $2 \mathrm{~h})$ did not result in increased inhibition. A further possibility is that there is also a small population of $A_{2}$ receptors present on this tissue opposing the $A_{1}$ effects of adenosine and resulting in apparently nonsurmountable antagonism by DPCPX, but although this possibility cannot be discounted no relaxation to adenosine or its analogues was revealed in the presence of the antagonist.

That the $\mathbf{P}_{2}$-purinoceptor antagonist, suramin, inhibited the effects of ATP and of AMPCPP but not of adenosine or AMPPCP confirms the selectivity of suramin for $\mathbf{P}_{2}$-purinoceptors and our previous conclusion (Bailey \& Hourani, 1990) that AMPPCP unexpectedly acts on $P_{1}-$ and not $\mathbf{P}_{2}$-purinoceptors in this tissue. That DPCPX, like 8-SPT (Bailey \& Hourani, 1990), dose-dependently inhibited the effects of AMPPCP in a similar fashion to those of adenosine also confirms that the major action of AMPPCP is via the $A_{1}$ receptors. Blockade of $P_{1}$ receptors with 8-SPT did reveal a $\mathrm{P}_{2}$ component to the action of very high concentrations $(\geq 100 \mu \mathrm{M})$ of AMPPCP (Bailey \& Hourani, 1990), and this might explain why suramin slightly inhibited the effect of $300 \mu \mathrm{M}$ AMPPCP (Figure 3b), and why DPCPX did not depress the slopes of the log concentration-response curves to AMPPCP to quite the same extent as those of adenosine (Figure 2). We have also observed this $P_{1}$ effect of AMPPCP in the rat duodenum and, to a lesser extent, in the guinea-pig taenia caeci, and as in all these tissues AMPPCP (unlike ATP) is highly resistant to degradation these effects are likely to be direct and not via its potential breakdown product adenosine (Bailey \& Hourani, 1990; Hourani et al., 1991).

Although DPCPX, like 8-SPT, did not inhibit the effects of ATP on the rat colon muscularis mucosae even at $10 \mathrm{nM}$, the results reported here show that suramin, which abolished the effects of the $P_{2}$ agonist AMPCPP, only partially inhibited the effects of ATP, and revealed a $P_{1}$ component of its action. In this tissue responses to $P_{2}$ agonists are slower than responses to $P_{1}$ agonists (see Bailey \& Hourani, 1990 for representative traces), and in the presence of suramin the response to ATP changed in nature, becoming faster and quickly reversing, like that to adenosine. This residual response was blocked by DPCPX, indicating that it was indeed mediated by the $A_{1}$ receptors in this tissue, and a combination of suramin and DPCPX abolished responses to ATP. It is not clear from these results whether this $P_{1}$ component of the effect of ATP is direct or is mediated by its rapid breakdown to adenosine.

In conclusion, the results presented here and those previously published (Bailey \& Hourani, 1990) show that in the rat colon muscularis mucosae contractile responses to purines are mediated by $A_{1}$ and $P_{2 Y}$ receptors, which can be selectively blocked by DPCPX and suramin respectively. Although adenosine and its analogues act only on the $A_{1}$ receptors and AMPCPP acts only on $P_{2 Y}$ receptors, the stable ATP analogue AMPPCP acts directly via the $A_{1}$ receptors and ATP itself also has an $A_{1}$ component to its action which can be revealed by suramin.

We thank the Medical Research Council for support for S.J.B. (Grant number G8723473N), and Bayer UK for kindly providing suramin.

\section{References}

BAILEY, S.J. \& JORDAN, C.C. (1984). A study of [D-Pro ${ }^{2}$, D-Phe ${ }^{7}$, D-Trp ${ }^{9}$-substance $P$ and $\left[D-T^{2}{ }^{7,9}\right]$-substance $P$ as tachykinin partial agonists in the rat colon. Br. J. Pharmacol., 82, 441-451.

BAILEY, S.J. \& HOURANI, S.M.O. (1990). A study of the purinoceptors mediating contraction in the rat colon. Br. J. Pharmacol., 100, 753-756.

BRUNS, R.F. (1990a). Structure-activity relationships for adenosine antagonists. In Purines in Cellular Signalling. ed. Jacobson, K.A.,

Daly, J.W. \& Manganiello, V., pp. 126-135. New York: SpringerVerlag.

BRUNS, R.F. (1990b). Adenosine receptors: roles and pharmacology. Ann. N.Y. Acad. Sci., 603, 211-226.

BURNSTOCK, G. (1978). A basis for distinguishing two types of purinergic receptor. In Cell and Membrane Receptors for Drugs and Hormones: A Multidisciplinary Approach. ed. Bolis, L. \& Straub, R.W., pp. 107-118. New York: Raven Press. 
BURNSTOCK, G. (1990). Purinergic mechanisms. Ann. N.Y. Acad. Sci., 603, 1-18.

BURNSTOCK, G. \& KENNEDY, C. (1985). Is there a basis for distinguishing two types of $\mathrm{P}_{2}$-purinoceptor? Gen. Pharmacol., 16, 433-440.

COLLIS, M.G. (1990). Adenosine receptor sub-types in isolated tissues: antagonist studies. In Purines in Cellular Signalling. ed. Jacobson, K.A., Daly, J.W. \& Manganiello, V., pp. 48-53. New York: Springer-Verlag.

COLLIS, M.G., JACOBSON, K.A. \& TOMKINS, D.M. (1987). Apparent affinity of some 8-phenyl-substituted xanthines at adenosine receptors in guinea-pig aorta and atria. Br. J. Pharmacol., 92, 69-75.

COLLIS, M.G., STOGGALL, S.M. \& MARTIN, F.M. (1989). Apparent affinity of 1,3-dipropyl-8-cyclopentylxanthine for adenosine $A_{1}$ and $A_{2}$ receptors in isolated tissues from guinea-pigs. $B r$. J. Pharmacol., 97, 1274-1278.

CUSACK, N.J. \& HOURANI, S.M.O. (1990). Subtypes of $\mathrm{P}_{2}$-purinoceptors. Studies using analogues of ATP. Ann. N. Y. Acad. Sci., 603, 172-181.

DALY, J.W. (1990). Adenosine agonists and antagonists. In Purines in Cellular Signalling. ed. Jacobson, K.A., Daly, J.W. \& Manganiello, V., pp. 3-12. New York: Springer-Verlag.

DEN HERTOG, A., NELEMANS, A. \& VAN DEN AKKER, J. (1989a). The inhibitory action of suramin on the $P_{2}$ purinoceptor in smooth muscle cells of guinea-pig taenia caeci. Eur. J. Pharmacol., 166, 531-534.

DEN HERTOG, A., VAN DEN AKKER, J. \& NELEMANS, A. (1989b). Suramin and the inhibitory junction potential in taenia caeci of the guinea-pig. Eur. J. Pharmacol., 173, 207-209.

DUNN, P.M. \& BLAKELY, A.G.H. (1988). Suramin: a reversible $\mathrm{P}_{2}$-purinoceptor antagonist in the mouse vas deferens. Br. J. Pharmacol., 93, 243-245.

FARMER, S.G., CANNING, B.J. \& WILKINS, D.E. (1988). Adenosine receptor-mediated contraction and relaxation of guinea-pig isolated tracheal smooth muscle: effects of adenosine antagonists. $\mathrm{Br}$. J. Pharmacol., 95, 371-378.

FEDAN, J.S. \& LAMPORT, S.J. (1990). $P_{2}$-purinoceptor antagonists. In Purines in Cellular Signalling. ed. Jacobson, K.A., Daly, J.W. \& Manganiello, V., pp. 182-197. New York: Springer-Verlag.

GORDON, J.L. (1986). Extracellular ATP: effects, sources and fate. Biochem. J., 233, 309-319.

HOURANI, S.M.O., BAILEY, S.J., NICHOLLS, J. \& KITCHEN, I. (1991). Direct effects of adenylyl $5^{\prime}-(\beta, \gamma$-methylene)diphosphonate, a stable ATP analogue, on relaxant $P_{1}$-purinoceptors in smooth muscle. Br. J. Pharmacol., 104, 685-690.

HOYLE, C.H.V., KNIGHT, G.E. \& BURNSTOCK, G. (1990). Suramin antagonizes responses to $P_{2}$-purinoceptor agonists and purinergic nerve stimulation in the guinea-pig urinary bladder and taenia coli. Br. J. Pharmacol., 99, 617-621.
JACOBSON, K.A. (1990). Molecular probes for adenosine receptors. In Purines in Cellular Signalling. ed. Jacobson, K.A., Daly, J.W. \& Manganiello, V., pp. 54-64. New York: Springer-Verlag.

KENAKIN, T.P. \& PIKE, N.B. (1987). An in vitro analysis of purinemediated renal vasoconstriction in rat isolated kidney. $\mathrm{Br} . \mathrm{J}$. Pharmac., 90, 373-381.

KENNEDY, C. (1990). $P_{1}$ - and $P_{2}$-purinoceptor subtypes-an update. Arch. Int. Pharmacodyn., 303, 30-50.

LEFF, P., WOOD, B.E. \& O'CONNOR, S.E. (1990). Suramin is a slowlyequilibrating but competitive antagonist at $P_{2 x}$-receptors in the rabbit isolated ear artery. Br. J. Pharmacol., 101, 645-649.

LEUNG, E., JACOBSON, K.A. \& GREEN, R.D. (1990). Analysis of agonist-antagonist interactions at $\mathrm{A}_{1}$ adenosine receptors. $\mathrm{Mol}$. Pharmacol., 38, 72-83.

OLSSON, R.A. \& PEARSON, J.D. (1990). Cardiovascular purinoceptors. Pharmacol Rev., 70, 761-845.

PEARSON, J.D. \& SLAKEY, L.L. (1990). Intracellular and extracellular metabolism of adenosine and adenine nucleotides. In Purines in Cellular Signalling. ed. Jacobson, K.A., Daly, J.W. \& Manganiello, V., pp. 13-19. New York: Springer-Verlag.

RIBEIRO, J.A. \& SEBASTIAO, A.M. (1986). Adenosine receptors and calcium: basis for proposing a third $\left(\mathrm{A}_{3}\right)$ adenosine receptor. Prog. Neurobiol., 26, 179-209.

SMITH, M.A., BUXTON, I.L.O. \& WESTFALL, D.P. (1988). Pharmacological classification of receptors for adenyl purines in guinea-pig myometrium. J. Pharmacol. Exp. Ther., 247, 1059-1063.

STOGGALL, S.M. \& SHAW, J.S. (1990). The coexistence of adenosine $A_{1}$ and $A_{2}$ receptors in guinea-pig aorta. Eur. J. Pharmacol., 190, 329335.

STONE, T.W. (1983). Purine receptors in the rat anococcygeus muscle. J. Physiol., 335, 591-603.

STONE, T.W. (1991). Receptors for adenosine and adenine nucleotides. Gen. Pharmacol., 22, 25-31.

VON KUGELGEN, I., BULTMANN, R. \& STARKE, K. (1990). Interaction of adenine nucleotides, UTP and suramin in mouse vas deferens: suramin-sensitive and suramin-insensitive components in the contractile effect of ATP. Naunyn-Schmiedebergs Arch Pharmacol., 342, 198-205.

WELFORD, L.A., CUSACK, N.J. \& HOURANI, S.M.O. (1986). ATP analogues and the guinea-pig taenia coli: a comparison of the structure-activity relationships of ectonucleotidases with those of the $\mathrm{P}_{2}$-purinoceptor. Eur. J. Pharmacol., 129, 217-224.

WELFORD, L.A., CUSACK, N.J. \& HOURANI, S.M.O. (1987). The structure-activity relationships of ectonucleotidases and of excitatory $\mathbf{P}_{2}$-purinoceptors: evidence that dephosphorylation of ATP analogues reduces pharmacological potency. Eur. J. Pharmacol., 141, 123-130.

WHITE, T.D. (1988). Role of adenine compounds in autonomic neurotransmission. Pharmacol. Ther., 38, 129-168.

(Received August 13, 1991 Revised September 11, 1991 Accepted September 24, 1991) 